\title{
An Ambidextrous Communication Strategy: Policy Makers vs Citizens
}

\author{
Giulia Netti ${ }^{1}$ \\ ${ }^{1}$ Department of Economics, Lum Jean Monnet University, Casamassima (Ba), Italy \\ Correspondence: Giulia Netti, PhD in the Economics and Management of Natural Resource, Department of \\ Economics, Lum Jean Monnet University, Casamassima (Ba), Italy.
}

Received: March 18, 2020

Accepted: April 8, 2020

Online Published: May 21, 2020

doi:10.5430/ijba.v11n3p93

URL: https://doi.org/10.5430/ijba.v11n3p93

\begin{abstract}
This paper is a qualitative research, deals with studying which communication strategy is used by politicians, whether explorational, exploitative, or ambidextrous communication and how citizens, instead, view such strategy choices carried out by politicians. Moreover, the study analyzes whether ambidextrous communication strategies allow citizens to achieve greater knowledge and awareness regarding sustainability issues (SDGs), compared to what occurs if the politician uses a different communication strategy.

The Study 1 was conducted through a semi-structured interview to Italian parliamentarians (senators and deputies) of the XVII and XVIII legislatures. The number of parliamentarians who agreed to the interview was 24 parliamentarians.

In the study 2 a survey was conducted on a sample of Italian citizens through various communication channels, mainly through Whastapp and Facebook. The final aim of survey to identify whether the joint use of both communication channels may reinforce citizens' awareness about sustainable development goals. The citizens what responded to the survey were 289 .

The results of the two studies show that the use of ambidextrous communication strategy, ie the joint use of the exploitative and explorational communications, is preferred by politicians to the use of only one of the strategies and that there is a positive correlation between the ambidextrous communication strategy of politicians and greater awareness of citizens about sustainability issues (SDGs). These results demonstrate that the hypotheses identified are supported.
\end{abstract}

Although this study has significant implications for how politicians should communicate, it also has different limits.

Keywords: communication, ambidexterity, sustainability, SDGs, communicational ambidexterity, politicians, citizens

\section{Introduction}

In this millennium the life of people, their perception, values and habits have been continually modified and altered by technological developments (Abruzzese, 2007). In particular, technologies have led to an evolution in the field of communication between people and their relationship within the same communication tools. This evolution has changed human life in that technologies represent "the elementary unit of self-organization and maintenance of time, for every living being" (Capra, 2001, p. 394). Think of communication methods in the past, such as letters, face-to-face meetings, as well as telephone, radio, TV, until today with the advent of the Internet and its continuous evolutions - from web 1.0 to web 4.0- in which everything has changed. If we observe this evolution under the entrepreneurial profile and the relationships between businesses and consumers, this has led to a change in the interaction among them, identifying a new figure called the "Prosumer", i.e., a co-producer consumer, well informed, critical and very active, which on the web is called "Produser" (Burns, 2009), namely an active and productive user.

The evolution and change in mankind also brings about change even in other areas. For example, substantial changes have been made in the area of politics and the consequent behaviors of citizens regarding politics.

This study has the objective of understanding how the choice of the communication strategy of Italian parliamentarians is made and how citizens, instead, view such strategy choices. The goal is to demonstrate that an ambidextrous communication, that is the joint use of exploitative communications and explorational communications, allows politicians to achieve more effective and efficient interactions. Furthermore, it wants to demonstrate that, 
thanks to the implementation of an ambidextrous political communication strategy, it is possible to achieve greater awareness of citizens about sustainability issues, as compared to the awareness that citizens have in learning information through the politicians' mere use of just exploration strategy (e.g., social channels) or just exploitation strategy (e.g., traditional channels). Moreover, it verifies citizens' satisfaction with the discussion of sustainability issues carried out by politicians, on traditional and/or social channels.

This chapter is composed of two studies. The first study was realized through a semi-structured interview with politicians, the second study through a questionnaire given to citizens.

\section{The Role of Communication in Society}

Communication has always been identified as a mutual interaction process in which the subjects have the ability to transmit information, producing culture which, in turn, generates meanings and information that are further shared by the recipients of the communication. This semiotic approach is based precisely on the transmission and exchange of meanings (Bettetini et al., 2005). Socialization processes (Reimann, 1982), regardless of the used means, allow for communication that generates meanings that are learned by the interlocutors. However, the vast literature, albeit with conflicting opinions, states that communication through traditional media causes effects both in the medium and in the long term, regardless of the statuses of the sender and the recipient. Indeed, whether it is a communication generated by a non-profit organization towards the stakeholders, or a corporate communication addressed to the consumer or a communication by a government agency towards its citizens, through the traditional media tool (TV, radio, print etc.), according to the so-called Hypodermic theory (Berger, 1995), the recipient is a passive subject that responds mechanically to stimuli, while, according to more positive theories such as the limited effects theories (Lazarfield, 1968) and uses and gratifications (Katz et al., 1974), the communication of traditional media has the ability to reinforce an attitude and/or a belief, rather than make a change, recognizing the recipient's ability to use these tools based on their own expectation of gratification and their own uses and customs. However, these theories are outdated by more recent cultural studies (Hoggart, 1958; Williams 1974) as seen in the definition of communication found by Semiotic theories (Bettetini, 2011).

The technological revolution has brought about a profound change in man's behavior and choices of communication, and human evolution itself cannot be read except through evolution and, therefore, the transformation of ways to communicate (Innis, 1951). The communication technologies represent a real evolutionary catalyst (Longo, 2004), whose changes are not easy to understand neither regarding the scope nor the direction (Scaglioni, 2008) because we are immersed in communication (Di Fraia, 2011).

The continuous process of technologies has led to the first occurrence of a unidirectional communication - which, therefore, represents communication realized through those channels that in this study will be identified as traditional, such as TV and radio - until reaching a bi-directional communication, realized, for example, thanks to the advent of social networks and blogs, here considered explorative communication tools. It should be remembered that the advent of traditional media (unidirectional communication) caused a first disturbing change in communication practices (Goffman, 1969), which subsequently continued in its evolutionary path.

\section{Exploitative Communications Between Citizens and Politicians}

The use of traditional channels, such as radio and TV, in the course of technological developments, has slowed their rise and such channels have had to resize the characteristics underlying the creation of messages, words and transmitted meanings. In the globalized context in which we find ourselves highly pro-active and full of commitments, the target segments of the radio and TV have changed their habits, listening to it not as a primary activity but rather as a secondary one (Chion, 1996).

Analogue and electrical media - from telegraphs to the advent of telephones, from TV to radio - were the forerunners of profound changes in communication, allowing for a wide dissemination of available information, neutralizing the spatial limit (in the case of telegraphs and of telephones) up to the time neutralization (Di Fraia, 2011) - in the case of TV and Radio. These tools still retain their importance, even if they have had to resize their role as communicational tools. The mass media can be considered real socialization agencies (Rosengren, 2001) since the communications they address to citizens and/or consumers generate experience in the interlocutor (Boccia Artieri, 2004).

In this study traditional channels are defined as those channels such as: radio, TV, interpersonal relationships implemented through face-to-face meetings, rallies, newspapers, leaflets and websites. In this study websites are included within the list of traditional channels because the cultural (Di Fraia, 2011) social and anthropological change is recognized, also due to their being overcome by new web tools, such as apps, social networks and blogs. 
The characterizing element for most of the traditional channels turns out to be a "one to many" communication, i.e., the presence of a single sender and a plurality of receivers, realizing a massification of information (Capecchi, 2004). These channels mostly have standardized content, rigid and not at all interactive (Boone, 2007), but are still effective when a part of the recipients are characterized by a low propensity to innovation, perhaps because they are elderly and therefore anchored to old visions and behaviors.

\section{Explorational Communication}

The progressive technological evolution has led to a greater weight of digital media highlighting the responsibility that these instruments hold, as vehicles of content, as instruments of connection between individuals and as protagonists of a new society, besides being engines of social and cultural dynamics (Ortoleva, 2009). The digital media have led to an evolution of society from a modern mass society (Bauman, 2002) to a network society (Castells, 2009). Networks are complex structures that are based on shared objectives in which they can exchange content and resources that are differentiated according to the referent. Furthermore, the messages are personalized, re-elaborated, enriched and shared, highlighting the great power of the interaction and, therefore, of "produsers" (Burns, 2009).

Social networks have become a real online information resource, where information circulates freely and deals with any subject (Blackshaw \& Nazzaro, 2004). In addition, social networks allow for the creation of an online profile as well as the possibility to communicate and be part of a more or less extensive network in which the contents are processed and reprocessed, leading them also to play a role of hybrid promotion tool, integrated into a communication system (Mangold \& Faulds, 2008). The interactions among the subjects are multiple. On the one hand they allow for organizations of any type to communicate with their own target and, on the other hand, for the people to communicate and interact with each other (Gillin, 2007). Nowadays they represent the fastest and most efficient tools among different interlocutors (Schneider, 2003). Anyone who wants to extend their network of relationships, through social networks can do so (Gabriel, 2002) and moreover, the contents are born from the interaction between users that generate meaning (Levine et al., 2001). All these advantages are grasped not only by private individuals but also by public entities, as shown by this study which refers to politicians and their presence on social networks, but also by companies, non-profit organizations, local authorities etc.

The advertising that circulates virally on social media is totally different from advertising seen on traditional channels such as TV and radio, in this case it is vital, credible and personal, in short, a perpetual file sharing (Genovese, 2011), leading to consensus (Ponchio, 2002),. In the case study consensus is sought out daily by politicians, involving social users to discuss different issues and to present themselves openly to the electorate, who evaluates their behavior and promises made both in the electoral campaign and with respect to the problems highlighted by the interactive conversation. Among other things, social media allow for having content for multiple supporters, making communication flows fluid (Jenkins, 2007).

As Chieffi (2012 p. 58) stated: "The digital relationship is, of course, the faithful transposition of the offline one, replicating and preserving the dynamics, characteristics, trends and rules [...] but not the environmental, cultural and socio-economic conditions nor the non-verbal and physical aspects of communication. This means that the digital relationship, online interaction, is placed on a different level, dematerialized and unconditioned, where the message itself takes the center stage of the interaction, devoid of that set of symbols, signifiers and meanings relating to non-verbal forms of communication, in a context free from supra-structural socio-cultural conditioning. It is therefore the message, the content, in its naked perceived meaning, the real pivot on which the online relationship rotates".

The politician finds, in the use of social media, the creation of an online relationship with the citizen through interaction with them and the ability to build their identity.

\section{The Importance of Communication on Sustainable Issues}

Sustainability guidelines are increasingly being undertaken by business organizations (American Management Association, 2007) but above all by national and international governments, such as the implementation of European directives in member states (such as Directive 2004/95 / EU, the Directive 2008/98 / EU, the EC Regulation No. 178/2002 and the Law No. 155/2003), and many other regulations on which Italian policy makers work daily, in order to make Italy a more sustainable nation, in terms of the economic, the environmental and social dimensions, in accordance with the European strategies and the objectives of sustainable development defined by the United Nations (SDGs). In reference to this work on sustainable development, carried out by Italian politicians and governmental bodies, the role of communication is of fundamental importance whether it is viewed from an exploitative communication perspective, from an explorational communication perspective, or through the implementation of both 
strategies. This affirmation is supported by many of the activities and projects implemented by the European Union, such as the Hi4CSR project or the Soci_SDG project, which are part of the Erasmus + strategic partnership, which have the task of training and informing all stakeholders about the importance of being sustainable. Citizens, public administration, businesses, non-profit organizations, consumers, banks, etc. are called to pursue sustainability goals.

Being sustainable means achieving and maintaining important goals in the long term (Crane \& Matten, 2007) including the dimensions identified in the Triple Bottom line (Elkington, 1997).

In order to be sustainable there is a need for each individual subject whether it be an individual or an organization or an entity, to know and be informed about these issues.

In the case of the Soci_SDG project, for example, communication involves both traditional channels, thus implementing a strategy of exploitative communication, and social networks, and therefore an explorational communication strategy, consequently achieving an ambidextrous strategy, which manages to involve a larger number of stakeholders.

The European Commission believes that the communication of these issues is of fundamental importance in order to implement good practices and consequently achieve the sustainability objectives (COM, 2011). The communication in this context assumes the task of helping to promote the development of a greater awareness of all stakeholders in order to create value, employment, growth, reduction of waste and pollution, etc.

In this chapter two different studies have been carried out, the first concerning a study on politicians, trying to demonstrate the following hypothesis:

H1: Italian politicians use an ambidextrous communication strategy rather than just the use of an exploitative communication or explorational communication strategy.

The second study is aimed at citizens and wants to demonstrate the following hypothesis:

$\mathrm{H} 2$ : The use of an ambidextrous communication strategy is positively correlated with a greater awareness on the part of citizens about sustainability issues.

\section{Study 1}

\subsection{Methodology and Sampling Procedure}

The first study was conducted through a semi-structured interview for seclected observers, in line with the definition of a qualitative interview defined by Corbetta $(1999$, p. 405) as "a conversation initiated by the interviewer, addressed to a substantial number of subjects chosen on the basis of a survey plan and, with fact-finding purposes, guided by the interviewer, based on a flexible non-standardized scheme of questions".

The selected observers, in our study, were Italian parliamentarians (senators and deputies) of the XVII and XVIII legislatures. Emails were sent inviting all above mentioned parliamentarians to participate in the interview. However, the number of parliamentarians who agreed to the interview was 24 parliamentarians, with a percentage of $45.83 \%$ of Senators and $54.17 \%$ of Deputies. The semi-structured interview was composed of some closed questions in which, for each element, the parliamentarians had to indicate a degree of preference according to the Likert scale, including values from 1 to 5 , in which 1 meant never, 2 rarely, 3 sometimes, 4 often and 5 always, or 1 not at all urgent, 2 slightly urgent, 3 moderately urgent, 4 very urgent and 5 extremely urgent, depends by questions. Followed by open-ended questions in which the flow of the discussion of the parliamentarians was followed, aimed at evaluating which of the communication strategies - i.e., exploitative communications, identified in the use of traditional channels, and explorational communication, identified in the use of social media, like Facebook, Twitter and Instagram - were used by them, and if they recognized the importance of using them together. Furthermore, the semi-structured interviews were recorded and then subsequently transcribed.

The duration of each interview was variable, but on average took about thirty minutes. Furthermore, the semi-structured interviews were carried out with the sole purpose of the present study and included not only questions concerning communication strategies - i.e., exploitative communication and explorational communication, but also questions concerning Sustainable Development Goals (SDGs). In particular, reference was made to some of the sustainable development objectives identified in the United Nations 2030 agenda. Specifically, the focus was on questions concerning Sdg 1 "No poverty"; Sdg 2 "Zero Hunger"; Sdg 3 "Good health and well-being"; Sdg 4 "Quality education"; Sdg 8 "Decent work and economic growth"; Sdg 9 "Industry, innovation and infrastructures"; Sdg 10 "Reduce inequalities"; Sdg 11 "Sustainable cities and communities"; Sdg 12 "Responsible consumption and production"; Sdg 16 "Peace, justice and strong institutions". The objective to be achieved through sustainable 
questions was to identify which SDGs, according to the interviewees, must be considered most urgent to be addressed in the sustainability implementation plan in Italy.

\subsection{Results}

From the analysis of the interview results, it emerged that approximately $87.50 \%$ of the interviewed parliamentarians agree that political communication must be carried out through the use of both strategies - i.e., exploitative and explorational communications; $4.17 \%$ ( 1 senator), on the other hand, believes that the use of social channels is more useful than traditional ones, while $8.33 \%$ ( 1 senator and 1 deputy) state that they are both important but prefer traditional forms of communication. Furthermore, it emerges that the choice of using both communication strategies (87.50\% of the interviewees) is conditioned by the "search for satisfaction of the different types of needs", as well as by the "need to keep pace with an increasingly complex society that is subject to constant demands of the media", by the "continuous technological evolution" and by the "fundamental objective of reaching all voters".

Among those who agree with the use of both forms of communication $(87.5 \%)$, a significant sample (25\%) highlighted a series of factors that underline and confirm some of the themes of the present research.

On the subject of relational and communicative aspects, for example, from the statements of Senator Lucio Malan, the importance of explorational communication as a communicational and interactive aspect emerges, and the importance of exploitative communication as a way to respond to the needs of the traditional culture of verification and the principle of rationality (Briggs and Burke, 2002), as explained in chapter 1. In this sense, Senator Lucio Malan stated that:

"Social media and the internet are greatly useful for initiating contact with many people and becoming a constant reference for those who want to follow us. However, neither the other types of media nor personal presence on certain occasions can be overlooked".

The proposition "personal presence on certain occasions" underlines the importance attributed to the circumstance in which the physical presence of the parliamentarian assumes the value of a testimony of the truthfulness of the "fact" of which one is speaking and of which the parliamentarian himself assumes the responsibility, even with his sole presence.

On the subject of communication quality, it is emphasized that although the use of explorational communication is fundamental as a communication strategy, this is not enough and sometimes presents limits, such as the generation of fake-news, which confuse citizens about what is true and what is false. A Deputy member of "Popolo della libertà" party, who is 50 years old and a Deputy member of "Partito democratico" party, who is 63 years old both commented on this topic. The "Popolo della libertà" Deputy said that:

"Communication on social media can no longer be stopped as a daily tool for the mass for knowledge and transparency; unfortunately, this is an alienating phenomenon and subject to "fake-news" that threatens to pollute the political debate and needs to find tools for its control. Unfortunately, I think the lowering of the quality of the ruling class also depends on the almost disappearance of traditional models, but I believe it is unthinkable to go back".

In which emerges the problem of false information and the near disappearance of all the channels first used in politics, making part of the exploitative communication.

However, in addition to the problem of fake-news, the problem of the need for greater efficiency and effectiveness of communication and citizen participation also emerges. Evidence of this is the statement by the aforementioned Deputy member of "Partito democratico" party:

"I believe that using both communication models is necessary. Obviously in a rational and, as far as possible, regulated manner. I think of the "fake-news" drama. I think of Socrates and truth as an objective definition. But I also believe that even this is not enough. Since the development of ever new and more effective forms of communication is desirable. From the palace to the citizen, so to speak. Moreover, the rapid technological and social development we are experiencing would allow us to rethink the entire system, at least in part. In a multilateral perspective, oriented to reciprocal exchanges between politician and citizen. In this sense, perhaps, the problem of communication is intertwined with that, always and forever fundamental, of participation".

To solve this problem, identified first by first the Deputy member of "Popolo della libertà" party, and then by the Deputy member of "Partito democratico" party, it is important to use both strategies, exploitative communication and explorational communication, pointing out that within the exploitative communication it is necessary to pay attention to identifying the right mix of traditional channels as explained by a Deputy member of "Centro democratico" party, who is 65 years old: 
"Obviously it is necessary to use all forms of communication, taking care to understand that the Italian public space is still a hegemony of television. The network, which by its nature is "destruens" and not "costruens", acts as background noise to a reputational path already affirmed on television. The printed paper is less incisive: the top ten daily newspapers sell together as much as "Il Corriere" ten years ago".

The two strategies are to be used together and must be well balanced in order to create the proper communication based on informational relationships and communicational relationships. According to a Senator member of "Partito democratico" party, who is 55 years old:

"Communication is very important for the purpose of disseminating the contents of the political proposal and must be useful in reaching the widest possible audience. The success of many technologies, accompanied by an increasingly spasmodic use of internet, also impose political parties to review tools and media. This does not, of course, mean giving up what was until a few years ago. Moments of physical aggregation such as debates, street meetings and the most classic means of communication, like press releases are just as important. The real challenge for politics and the representatives elected by the citizens is to organize the set of tools available, to make ourselves available to listen to and meet for face to face discussions with the electorate, the potential offered by the web or technologies available, stimulating participation without, however, being obsessed by "likes" of which we risk remaining prisoners".

While a Deputy member of "Partito democratico" party, who is 41 years old explained:

"Direct contact and the physical involvement of people is fundamental, but it is undeniable that politics should experiment with new forms of communication also to adapt to the changing styles and times of life that make participation in now obsolete party rites more difficult. The use in particular of online referendums, which however do not serve to merely consecration decisions already taken elsewhere and are effectively controlled and transparent, can be an effective form of active involvement in political life given the ever increasing distance and mistrust of citizens towards parties and institutions perceived as distant and unrepresentative".

Ultimately, even from this first question during the interviews it emerges that there is a profound need to use both strategies, because one cannot be pursued at the expense of the other, since by making this choice credibility would be lost and parts of the non active public in the single chosen strategy would be lost.

Questions were asked about the importance of traditional channels - i.e., exploitative communication - and social channels - i.e., explorational communication that politicians use most to inform and communicate with citizens. Specifically, the traditional channels were identified as: press releases, the parliamentarian's personal site, the party's website, public debates in the streets, and participation in television programs, newspapers, newscasts, direct door-to-door contacts, word of mouth and leafleting. Instead, as far as the choice of social channels is concerned, the following channels were taken into consideration in the arrangement of the questions related to explorational communication: Facebook, Twitter and Instagram.

From the results of the interviews the need to use both exploitative communication and explorational communication emerges, albeit with very different preferences regarding the use of individual channels in particular. For example, analyzing the exploitative communication compared to all the channels identified, this study shows that the traditional channels most used by Italian parliamentarians are: press releases (70.84\%), public debates (58.33\%), participation in television programs $(62.50 \%)$, newspapers $(70.84 \%)$, door to door meetings $(66.67 \%)$ and word of mouth (83.34\%); while traditional channels such as: the party's website and leaflets are little used. With regard to personal websites and newscasts, the results were equal values compared to the two categories identified (50\%), i.e., it emerges that these latter two channels are considered important for $50 \%$ of parliamentarians and not important for the remaining $50 \%$.

In the channels identified as means of explorational communication, ie Facebook, Twitter and Instagram, interviews showed that they are all channels used by the majority of parliamentarians interviewed, but that the use of Facebook is considered fundamental by $95.84 \%$, followed by Instagram with $70.84 \%$ and Twitter with $66.67 \%$.

The criteria that led politicians to use a certain communication channel compared to others emerged from the interviews. In the ambit of the exploitative communication, the criteria fell on: considerable importance and interest of the topic, expected communicative effect and age of the electorate to be reached, media coverage, qualified audience (experts), for example a Senator member of "Partito democratico" party, who is 55 years old said:

"I choose the communication channel based on the content and above all the target to be reached. Through press releases, for example, I communicate - with a more institutional approach -institutional activity or sharing of political positions". 
A Deputy member of "Lega Nord" party, who is 60 years old adds:

"We choose television and the press to reach citizens who are more inclined to be informed".

Compared to the criteria that emerged in the choice of the explorational communication, these are identified as elimination of space-time limits, immediacy, age of the citizens - the youngest - general description of the activities carried out by the parliamentarian, sharing and interaction, socialization and exchanging of points of view and ease use. In particular, a Deputy member of "Partito democratico" party, who is 31 years old stated:

"If, for example, I make a call for action or I want to inform my community, then I tend to use social networks".

A Deputy member of "Partito democratico" party, who is 41 years old declared:

"Immediacy, the possibility of reaching a vast public in a short time, the ability to be visible and to become central to public debate. In particular, social networks allow for this type of communication. I mainly use Facebook to make my position known on issues at the center of the political agenda or events that need immediate commentary and also the need for interaction with those who follow me and search for a better understanding or who want to deepen their knowledge of my political choices".

While, a Senator member of "Partito democratico" party, who is 55 years old added:

"On social networks I try to build a storytelling to trace the profile of my political commitment and my way of understanding relationships, affections, the relationship with what surrounds me using even more personal traits. On social networks I prefer more immediate texts, shorter videos or easy-to-read webcards, ideal for trying to attract attention while the user scrolls his message boards".

Concerning the motivations that lead a parliamentarian to use some communication channels than others, the interviewees revealed that in the context of exploitative communication the motivations can be found in the diffusion of information on specific topics for citizens who do not follow social networks; carrying out of institutional communications; acquiring voters; reaching the affiliated audience; creating strong bonds based on truthfulness and political responsibility; entering people's homes and workplaces. In particular, A Deputy member of "Lega Nord" party, who is 60 years old stated:

[...] "other channels such as the press and television help reach an audience that prefers to be informed by credible sources, regardless of the contribution of the individual politician".

While a Deputy member of "Lega Nord" party, who is 42 years old declared:

"In politics, I think it is important to expose oneself and expose one's ideas directly. Face to face communication is what makes contact with the electorate more effective".

A Deputy member of "Movimento 5 stelle" party, who is 61 years old stated:

"Adherence to the reality with whom you intend to interface. In a small center, for example, direct contact is important".

As regards the motivations that push the use of explorational communication, these are found in: the ability to converse with and acquire of new readers; reaching a younger and wider audience in a short time and on a continuous basis; reaching groups of people not belonging to affiliated audiences and the immediate and direct contact. In fact, as a Senator member of "Lega nord" party, who is 57 years old stated:

"Today people are always very connected and shared information on social networks reaches many web users".

While a Senator member of "Partito democratico" party, who is 55 years old stated:

"The reasons are simple. Looking at any report on statistics related to the use of media it is possible to outline - in broad terms - the user's profile. It is easy to guess that a few 80 year olds will have joined the Telegram channels and there will instead be many young people who browse Instagram stories instead of leafing through the pages of a beautiful newspaper. Unfortunately, we are a country where we read less and less but we share memos on Facebook. Each social network is different for each type of user, for its penetration and dissemination of the contents. This also produced distortions in the communication system: today, in many cases, news agencies are forced to follow posts and tweets".

In fact, from the answer about the reasons that lead to the use of exploitative communication and explorational communication, not only positive but also negative aspects are found. First of all, as A Senator member of "Forza Italia" party, who is 54 years old stated

"All channels are important in a right mix". 
However, the effectiveness and efficiency of each individual communication channel must be considered, for this reason it is important to have a correct balance of communication strategies, since in effect, as a Senator member of "Partito democratico" party, who is 50 years old stated:

"The effectiveness of the tool depends on how much they are able to 'modify' the consent and not only on how many people they can reach. I would say, in fact, it is necessary to distinguish between political information and political communication".

Indeed, explorational communication strategies reflect positivity in terms of space-time relations and immediacy with citizens, as stated by a Deputy member of "Partito Democratico" party, who is 32 years old:

"Immediacy, even if often it is at the expense of this same information. The need to communicate everything immediately and to make a news captivating often reduces its value".

In this sense, the reduction in the value of information can be overcome thanks to the implementation also of the exploitative communication.

From what has emerged so far, in regard to the first results of the interview, these confirm that in order for there to be a more effective and efficient communication, that reaches all types of audience and that meets all needs - identified in the Theory of uses and gratifications (Katz et al., 1974) - there is a need to implement both strategies, both exploitative communication and explorational communication, creating a new strategy called communicational ambidexterity.

According to the interviewees, concerning the problems of choosing communication channels during the run up to the elections, that is, in full electoral campaign, this evidence manifests itself explicitly. In fact, all the interviewees declared that there is a need to use as many channels as possible, and if, through the social channels, one can keep a record of the events, dates and share opinions; the traditional means are close support for this because the direct contact with the people and the sense of responsibility that a politician reveals through his presence, lead to moving closer or not to that particular political idea and to the consequent vote.

Moving on to the analysis of the answers concerning the importance and motivations of each Member of Parliament in regard to the pursuit of sustainability objectives, it emerges that the entire sample interviewed considers these objectives to be important. Some responses compared to others were stronger and more incisive. For example, a Deputy member of the "Partito democratico" party, who is 63 years old affirmed:

"I believe that, in an increasingly unequal world, a re-orientation of development in a sustainable sense is not only important, but quite essential; because development will be sustainable, or it will not exist at all. And, fortunately, more and more people understand this. We must act accordingly. I also believe that the general principle of sustainable development, now fundamental, must be implemented in all its dimensions: both the one related to the pursuit of an economic and social policy aimed at reducing poverty, protecting health, granting access to education for everyone and everywhere and gender equality; and that related to social truth, the cultural integration of peoples and the correct management of innovation. In particular, only a coherent and coordinated implementation of these policies, which are connected and mutually reinforcing, can contribute to the realization of social justice and substantial equality. A project, not a dream. In this context, it is clear that the fight against climate change and pollution - even in this case, the ones who pay the highest price are, above all, the poorest - is a case in point. I believe that, in some way, the ecological challenge is the great challenge of our time. But I'm optimistic, because I also believe in mankind".

From this statement it is clear that the sustainability objectives should be considered as real projects to be implemented, the optimism of this parliamentarian is evident in wanting to face this great challenge with optimism and trust in the human race.

The pursuit of sustainable development and the achievement of these objectives are identified as in the new light by which to be led. In this sense A Senator member of "Partito democratico" party, who is 50 years old stated:

"Sustainability must be the guiding light and the horizon of every local, regional and national government action in the different environmental, social and occupational dimensions. Concrete measures must immediately therefore be contained in the various institutional Programming Plans, converging with the objectives of the 2030 European strategy".

Moreover, the various interviewees believe that these arguments should not be considered as a corollary of an electoral program but as the engine of a different model. In particular, the importance of growth in terms of sustainability is fundamental and the main task of the captain of change must be assumed by politics, so as to reflect 
what was stated by a Senator member of "Partito democratico" party, who is 55 years old and who also distinguishes well-being from good-having:

"Growth is sustainable or not. Therefore, I believe that we can and must make development guaranteeing rights, keeping the accounts in order and preserving the environment that we have borrowed from our children. From this point of view politics must regain possession of a primacy, it must return to being strong in order to return to its function, which is to put itself at the service of the people, to redistribute wealth, to create better conditions for not leaving anyone behind. Well-being must not be confused with "well-having".

During the interview questions were asked about the sustainability issues taken in specific analysis in this study. The questions were aimed at understanding the degree of urgency - given by parliamentarians - with respect to the various sustainability issues to be addressed.

The results obtained show that the interviewees consider the following to be the more urgent issues: no poverty $(100 \%)$, quality education, employment / unemployment, innovation and pollution with $95.83 \%$, good health and well-being, sustainable cities and communities and justice with $91.67 \%$, help to industry $(87.50 \%)$, responsible consumption and production (83.33\%), reducing inequalities (79.17\%), zero hunger with $58.33 \%$.

In relation to the last question asked to the interviewees about the resolutions of the problems highlighted by the citizens both through traditional channels - exploitative communication, and with respect to social channels explorational communication - it emerges that the interviewees face these problems thanks to the promotion of laws, informative questions, amendments, urgent interpellations, communications aimed at raising awareness. All this as a Deputy member of "Partito Democratico" party, who is 63 years old explained:

"The problems of the citizens are everyone's problems! A law can sometimes be enough to solve them. At other times there is also a need for concrete implementation by the administrative structures, on every level. Often also the involvement of private individuals and associations representing interests can help solve problems".

From this statement we find that the implementation of the change is that the sustainability objectives seen in their social, economic and environmental dimensions, involve everyone and that all the stakeholders (Clarkson, 1995) are the players of the change, confirming what we said in the first chapter.

\section{Study 2}

After having analyzed the perspective of politicians in relation to the development of an ambidextrous communication strategy, the second study aims at identifying citizens' perceptions about the sustainable development goals communicated by politicians through traditional communication channels (i.e., exploitative) and social media (i.e., explorational). To this end, a survey was conducted on a sample of Italian citizens with the final aim to identify whether the joint use of both communication channels may reinforce citizens' awareness about sustainable development goals.

\subsection{Methodology and Sampling Procedure}

The sampling method used to extract the subjects from the reference population is non-probabilistic. The same method of administering the survey raises two questions: the problem of non-representativeness of the sample compared to the Italian population and the problem of the auto-selection of the sample. Both lead to distortion in the inference on the general Italian population. The first question is related to the way the survey is administered, that is on the web, in this way subjects who are very active online and on social media are reached, mostly young people and those at ease with electronic devices. The question of self-selection, typical of non-probabilistic surveys, concerns the way in which those who come into contact with the interviewer choose whether or not to respond and / or complete the survey. In general, it is assumed that those who voluntarily choose to submit to the survey are interested in the proposed topic and therefore have particular characteristics that distinguish them from the rest of the population. The selection mechanism in the data analysis will therefore have to be considered.

\subsection{Sample Description}

The socio-demographic characteristics of the sample confirm the suspicions of discrepancy with the Italian electoral population, presented in Figure 1. 


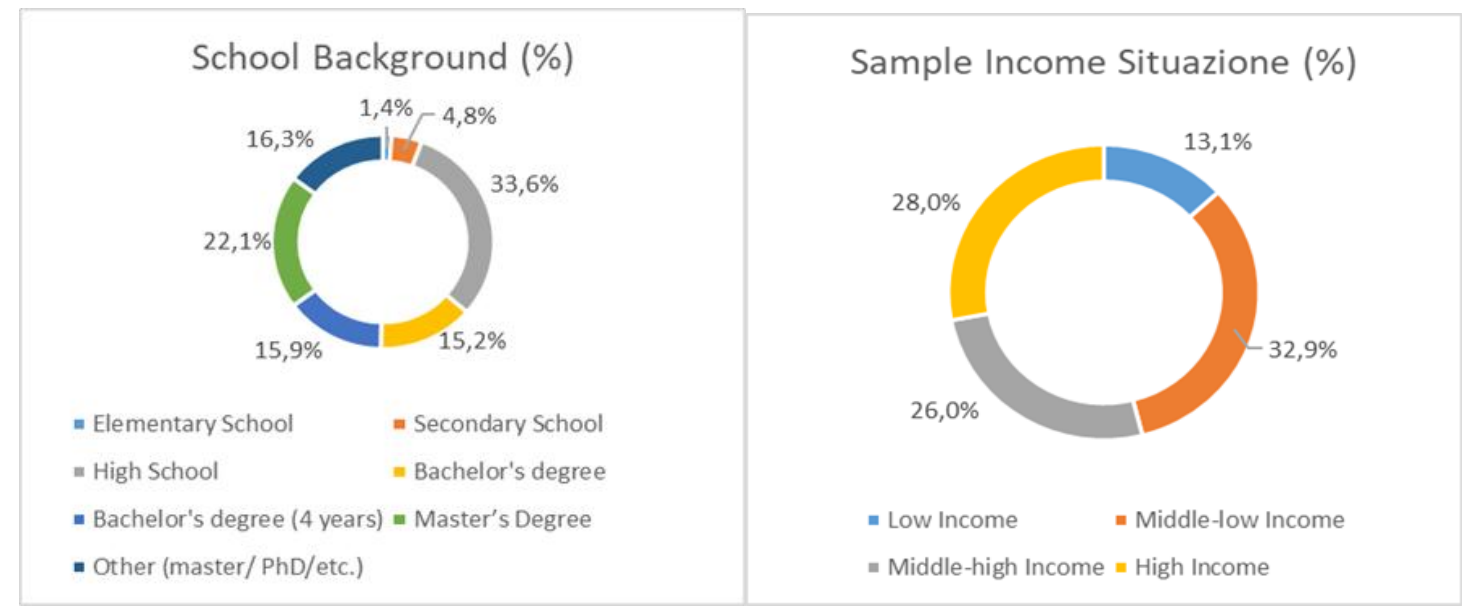

Figure 1. Sample statistics: qualifications and income

As for the qualification, more than half of the subjects interviewed achieved at least a first level degree against $18 \%$ of the working age population and $28 \%$ of $30-35$ year olds (as per ISTAT source). It is therefore a sample with certain characteristics: highly educated and with a slightly lower median age (42 against 45.5).

Direct participation in political life through membership of a party is significantly higher, $16 \%$ of the sample declares to be enrolled in a political party and although there are no official data on the registration of parties in Italy they should be between 1 and $2 \%$. The self-selection is therefore confirmed on the basis of interests: those who participated in the survey have, on average, a tendency to be interested in politics.

Retired and unemployed are confirmed by a sample taken from a medium-to-high income population. Regarding the age of sample and professional life of interviewees (figure 2) shows the characteristic of our sample.

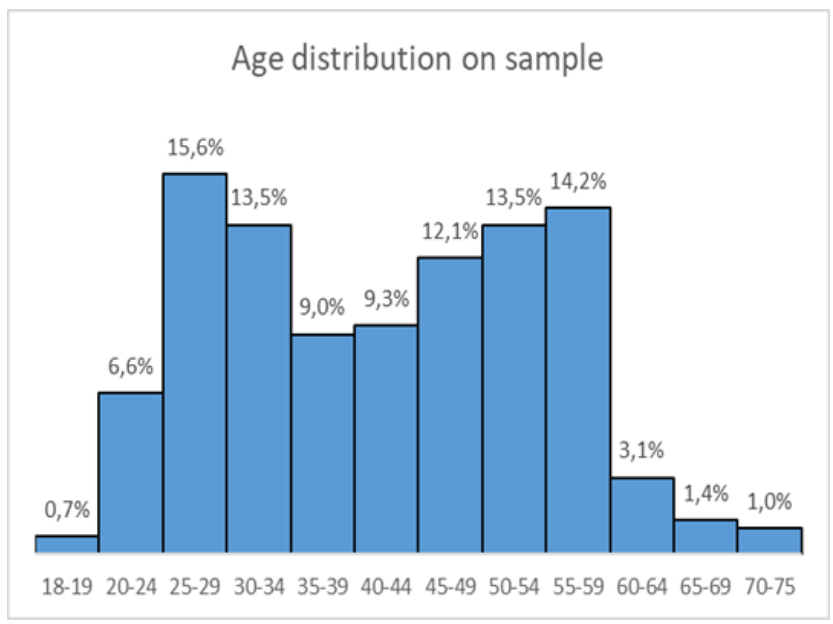

Figure 2. Age distribution and professional's life of sample

The sample was mainly composed of young people and people who are employed.

Regarding the preferences on informational tools the data shows (see figure 3) that for traditional channels - i.e., exploitative communication - the interviewees indicate as their favorite tools of information: TV (76.1\%), Web $(64.7 \%)$, newspapers $(48.1 \%)$. For explorational communication - e.g., social media channels $-55 \%$ indicate that they prefer it. 


\begin{tabular}{ll}
\hline Profession & \\
\hline Permanent employee & $38 \%$ \\
\hline Freelance & $20 \%$ \\
\hline Temporary employee & $11 \%$ \\
\hline Other & $8 \%$ \\
\hline Student & $7 \%$ \\
\hline Unemployed & $6 \%$ \\
\hline Entrepreneur & $4 \%$ \\
\hline Retired & $3 \%$ \\
\hline
\end{tabular}

Figure 3. Preference on information source

\subsection{Results}

In order to measure forms of traditional and social communication used, indicators were constructed to offer a measure relating to the prevalent aspects of use of the media, awareness of socio-economic problems and satisfaction with the communication of politicians on social media.

The variables studied were identified as follows:

- Traditional: the sum of the scores relative to the questions of the questionnaire on the use of traditional means of communication for information (TV, newspapers ...).

- Social: the sum of the scores obtained on the use of social media as a source of political information and on the activity on them (registration).

- Joint: sum of traditional and social, a high score in this index is a sign of a joint use of both social and traditional sources.

- Satisfaction: sum of the scores on the questionnaire questions on the satisfaction of political communication on social media in relation to certain topics related to sustainability.

- Awareness: the sum of the scores that the interviewed subjects self-attribute regarding their awareness and therefore their level of information on sustainability issues.

A correlation matrix has been created, as shown in Table 1.

Table 1. Index correlation matrix

\begin{tabular}{llllll}
\hline & Awareness & Social & Traditional & Joined & Satisfaction \\
\hline Awareness & 1.00 & & & & \\
\hline \multirow{2}{*}{ Social } & 0.20 & & & & \\
\hline \multirow{2}{*}{ Traditional } & $(0.00)$ & 1.00 & & & \\
\hline \multirow{2}{*}{ Joined } & 0.29 & 0.28 & & & \\
\hline \multirow{2}{*}{ Satisfaction } & $(0.00)$ & $(0.00)$ & 1.00 & & \\
\hline
\end{tabular}


The correlation matrix shows the link between these variables. In particular, we are interested in verifying whether a joint use of social media and traditional media increases awareness compared to the use of only social media or only traditional channels. The correlations with the awareness index are all positive (Pearson correlation index).

Our hypothesis $(\mathrm{H} 2)$ that the use of a communicational strategy by politicians is positively correlated with a greater awareness of citizens about sustainability issues is supported by our results.

\section{Discussion}

The first definition of ambidextrous strategy found in literature (March, 1991) defines exploitation strategy as a "refinement, choice, production, efficiency, selection, implementation, execution" of competences and practices; while, exploration relates to "research, variation, risk taking, experimentation, play, flexibility, discovery, innovation" practices and competence (March, 1991, p. 71). The use of both strategies, both exploitation and exploration, lead to defining the ambidexterity.

Many authors have studied this new ambidextrous strategy within the organization (Gupta et al., 2006; Katila and Ahujia, 2002; Lavie and Tushman, 2010; Jansen et al., 2012; He and Wong, 2004, Minojia, 2012, Brayson et al., 2008). However, although literature on ambidexterity has been increasing more and more in recent years and the past studies that examined the ambidextrous strategy focusing on innovation (Gupta et al., 2006), and the tradeoff between efficiency and flexibility (Adler et al. 1999), with respect to a temporal and structural dimension (Jansen et al., 2012) - and so on - in the literature there is a lack of studies that investigate ambidextrous strategy in the field of external communication, i.e. between companies and stakeholders, between Governments and stakeholders, between politicians and citizens.

In this sense, taking inspiration from the vast literature on ambidextrous strategy it has been possible to realize the theoretical framework of communicational ambidexterity, seen in the first chapter and applied specifically in this second chapter on the study of Italian politicians and citizens. In particular, the results that emerged from the interviews with Italian parliamentarians showed that our H1 hypothesis is supported and that therefore Italian politicians prefer to implement an ambidextrous communication strategy with compared to the use of only exploitative communication or only explorational communication, if want (as the results have shown), to satisfy the uses and gratifications (Katz, 1979) of the citizens because in this way they are more effective and more efficient.

While the results of the second study show that citizens have greater awareness of sustainability issues if politicians use an ambidextrous communicational strategy with compared to the use of exploitative or explorational communication strategies only. And so these results also confirm our second $\mathrm{H} 2$ hypothesis.

\section{Implications and Conclusions}

Communication plays a very important role in all social, economic and political contexts (Harvey and Griffith, 2002; Liotta et al, 2005; Doloi, 2009).

This study wanted to study political communication on both the politicians 'and citizens' sides. The first objective that it wanted to achieve through study 1 is to demonstrate that the joint use of exploration communication and exploitational communication allows politicians to achieve more effective and efficient communication. While thanks to study 2, the objective was demonstrate that an ambidextrous communication strategy provides a greater awareness of the information acquired by citizens.

If social media are becoming increasingly important in the daily life of each individual, because they use sharing as the basis for the creation of new groups / communities (Shirky, 2009), however the results show that the use of an ambidextrous communicational strategy, that is, the joint use of the exploitative and explorational communications, is preferred to the political use of only one of the strategies. Consequently, our hypothesis $\mathrm{H} 1$ belonging to the study is supported. With reference to the study on citizens, the results also support our $\mathrm{H} 2$ hypothesis demonstrating that there is a positive correlation between the ambidextrous communicational strategy of politicians and a greater awareness of citizens about sustainability issues. Ultimately, the results of the first study show how and which ones are the traditional channels - exploitative communication - and the social ones - explorational communication channels - used in the field of communication between politicians and citizens.

While the second study highlights which channels are used by citizens according to their preferences, also to inform themselves about sustainability issues. The results show that in both studies there is a need to use both strategies, and therefore both channels, since it would be possible to satisfy all the needs belonging to citizens that characterize a certain type of audience (Katz et al. 1974). This, as far as politics is concerned, has a remarkable impact both in terms of reaching the entire audience and in terms of the informational relationship and in terms of the 
communication relationship. For a politician, being recognized by the citizens as both a person who satisfies the principle of rationality - that is, responsibility and authenticity of the fact, of which the politician is speaking through traditional channels - and the principle of participation - establishing a direct debate with citizens through social media - makes the politician himself more credible and the truthfulness of what he professes is recognized, and also makes the whole audience more satisfied.

\section{Limitation and Futures Research}

Although this study has significant implications for how politicians should communicate, it also has different limits. First of all, it must be considered that the sample of the second study (289 answers) is characterized by the strong presence of a young audience and that around 50\% of the interviewees have college degrees. Therefore, it is important to increase the number of answers of the questionnaire to obtain a larger sample to include more elderly citizens, so as to better compare the differences and peculiarities that can be established between the preference for traditional channels and social channels by Italian citizens, which could lead to a different result than the analyses carried out so far. Secondly, the exact combination of traditional channels and social channels should be studied, to verify which combination of the different media present in the different channels leads to greater performance in political communication and greater public awareness of sustainability issues.

\section{References}

Abruzzese, A., \& Mancini, P. (2007). Sociologie della comunicazione. Laterza \& Figli, Roma-Bari.

Amrican Managemtent Association. (2007). Sustainability: An Evolving Business Paradigm.

Baumans, S. (2002). Modernità liquida. Laterza, Roma-Bari.

Berger, A. A. (1995). Essentials of mass communication theory. London: SAGE Publications. https://doi.org/10.4135/9781483345420

Bettetini, G. (2011). Non solo semiotica. Cinquant'anni di studi sulla comunicazione. Franco Angeli, Milano.

Bettetini, G., Calabrese, O., Lorusso, A. M., Violi, P., \& Volli, U. (2005). Semiotica. Raffaello Cortina, Milano.

Blackshaw, P., \& Nazzaro, M. (2004). Consumer-Generated Media (CGM) 101: Word-of-mouth in the age of the Web-fortified consumer.

Boccia, A. G. (2004). I media-mondo. Maltelmi editore, Roma.

Boone, L. E., \& Kurtz, D. L. (2007). Contemporary marketing, Mason. OH: Thomson/South-Western.

Briggs, A., \& Burke, P. (2002). Storia sociale dei media: da Gutenberg a internet. Soc. Ed. Il Mulino.

Capecchi, S. (2004). L'audience 'attiva'. Effetti e usi sociali dei media, Carocci, Roma.

Capra, F. (2001). La rete della vita. Rizzoli, Milano.

Castells, M. (2001). Galassia internet. Feltrinelli, Milano. .

Chieffi, D. (2012). Social Media Relations. Comunicatori e communities, influencers e dinamiche sociali nel Web. Le P.R online nell'era di Facebook, Twitter e blogger.

Chieffi, D. (2012). Social media relations: comunicatori e communities, influencers e dinamiche sociali nel web: le PR online nell'era di Facebook. Twitter e blogger. Gruppo 24 ore.

Chion, M. (1996). Musica, media e tecnologie: un manuale per capire, un saggio per riflettere Il saggiatore. Milano.

Clarkson, M. E. (1995). A stakeholder framework for analyzing and evaluating corporate social performance. Academy of Management Review, 20(1), 92-117.

Crane, A., \& Matten, D. (2007). Busines is Ethics (2nd ed.). Oxford University Press, New York.

Di Fraia, G. (2011). "Comunicare l'impresa: la sfida di internet e dei social media" in Di Fraia G. (a cura di) Social media marketing. Hopeli, Lavis (TN).

Di Fraia, G. (2011). "Sviluppi tecnologici e processi comunicativi: immagini di una rivoluzione in corso" in Di G. (a cura di) Social media marketing. Hopeli, Lavis (TN)

Doloi, H. (2009). Relational partnerships: the importance of communication, trust and confidence and joint risk management in achieving project success. Construction Management and Economics, 27(11), 1099-1109. https://doi.org/10.1080/01446190903286564 
Elkington, J. (1997). Cannibals with Forks. The Triple Bottom Line of 21st Century Business. Capstone Publishing, Oxford. https://doi.org/10.1002/tqem.3310080106

Gabriel, P. (2002). 3ème Congrès International du Marketing. Les logiques d'un marketing pragmatique orienté marché.

Genovese, A. (2011). Le nuove regole del marketing, in Di Fraia G. (a cura di) Social media marketing. Hopeli, Lavis (TN).

Gillin, P. (2007). The new infiuencers: A marketer's guide to the new social media. Sanger, CA, Quill Driver Books.

Goffman, E. (1986). La vita quotidiana come rappresentazione. Il Mulino, Bologna.

Harvey, M. G., \& Griffith, D. A. (2002). Developing effective intercultural relationships: The importance of communication strategies. Thunderbird International Business Review, 44(4), 455-476. https://doi.org/10.1002/tie.10029

Hoggart, R. (1958). The Uses of Literacy. Penguin, London.

Innis, H. A. (1951). The bias of communication, Toronto University of Toronto Press; trad. it. Le tendenze della comunicazione. Milano, SugarCo.

Jenkins, H. (2007). Cultura convergente. Apogeo, Milano.

Katz, E., Blumler, J. G., \& Gurevitch, M. (1974). The uses of mass communications: Current perspectives on gratifications research. Thousand Oaks, CA: Sage publications.

Lazarfield, P. (1968). The people's choiche: how the voter makes up his mins in a presidential campaign. Columbia University Press.

Levine, R., Locke, C., Searls, D., \& Weinberger, D. (2001). The Cluetrain Manifesto: The End of Business as Usual. Fazi Editore, Roma.

Liotta, L. A., Lowenthal, M., Mehta, A., Conrads, T. P., Veenstra, T. D., Fishman, D. A., \& Petricoin III, E. F. (2005). Importance of communication between producers and consumers of publicly available experimental data. Journal of the National Cancer Institute, 97(4), 310-314. https://doi.org/10.1093/jnci/dji053

Longo, G. O. (2004). La cultura delle reti. In A. Boccia, \& G. Mazzoli (Eds.), Tracce nella rete (pp. 8-25). Franco Angeli, Milano.

Mangold, W. G., \& Faulds, D. J. (2009). "Social media: the new hybrid element of the promotion mix" in Businessù Horizons. Indiana University, 52, 357-365. https://doi.org/10.1016/j.bushor.2009.03.002

Morace, F., \& Lanzone, G. (2010). Verità e bellezza. Nomos Edizioni, Busto Arsizio.

Ortoleva, P. (2009). Il secolo dei media, Il Saggiatore. Milano.

Ponchio, A. (2002). Internet come mezzo di comunicazione commerciale. Hops Libri, Milano.

Prunesti, A. (2016). Social media e comunicazione di marketing. Presidiare la Rete, costruire relazioni e acquisire clienti innovando l'esperienza utente. Franco Angeli, Milano.

Reimann, H. (1982). Introduzione alla sociologia, Il Mulino. Bologna.

Rosengren, K. E. (2001). Introduzione allo studio della comunicazione, Il Mulino. Bologna.

Scaglioni, M., \& Sfardini, A. (2008). Multi Tv. L'esperienza televisiva nell'età della convergenza. Carocci, Roma.

Schneider, G. (2003). Report on web marketing tools. Frin Verlang.

Shirky, C. (2009). Uno per uno, tutti per tutti. Il potere di organizzare senza organizzazione. Torino: Codice Edizioni.

Thompson, E. P. (1963). The English Working Class. Penguin, London.

Tönnies, F. (2011). Comunità e società. Laterza, Bari.

Williams, R. (1961). The Long Revolution. London and New York: Columbia University Press. https://doi.org/10.7312/will93760

Williams, R. (1974). Television: Technology and Cultural Form. London: Fontana. 